\title{
La educación antes y después de Internet
}

Kliksberg, Naum*

\author{
En la investigación científica \\ la imaginación es más importante \\ que el conocimiento \\ Albert Einstein
}

\section{Resumen}

En este ensayo se discuten los alcances y limitaciones que tienen que ver con el potencial de INTERNET en Educación vinculados con los modelos de educación, "memorística" y el modelo democrático que supone el desarrollo del "pensar creativo". Se considera que para alcanzar un (adecuado) desarrollo se hace necesario utilizar métodos de enseñanza-aprendizaje que le permitan al alumno alcanzar un nivel de elaboración creativa de la información, para lo cual el INTERNET puede convertirse en una herramienta útil.

Palabras clave: Modelo de educación, Internet, creatividad, aprendizaje, democracia.

Recibido: 99-11-16. Aceptado: 99-12-08

* Psicólogo y sociólogo. Se ha desempeñado como consultor de las Naciones Unidas, de la Organización Mundial de la Salud, de la Organización de Estados lberoamericanos, del Partamento Latinoamericano, de la Presidencia de Venezuela, y del Gobiemo de la Ciudad de Buenos Aires. Ha sido Profesor y Asesor en numerosas Universidades de diversos países latinoamericanos. Es autor entre otras obras de "La crisis pedagógica de las Universidades Latinoamericanas"(Universidad Central de Venezuela). Esta preparando actualmente la obra "Métodos de enseñanza. Aprendizaje de la pedagogía autoritaria y de la pedagogía democrática en los sistemas educativos en el mundo". 


\section{Education Before and After Internet}

This essay discusses the achievements and limitations that have to do with the use of INTERNET in education which are related to educational models, "memorization" and the democratic model that supposes the development of critical thought. To achieve an adequate level of development, it is considered necessary to utilize teaching-learning methods that allow the student to reach new levels of creative elaboration of information. In this sense INTERNET could become a useful instrument.

Key words: Educational model, Internet, creativity, learning, democracy.

\section{Introducción}

En este momento los sistemas educativos presentan un escenario en el que antiguos conceptos y métodos pedagógicos pierden vigencia y chocan con nuevos que empiezan a imponerse: "la inteligencia emocional", "enseñar a pensar", "elaboración creativa", son propuestas que plantean nuevos objetivos educativos y originan novedosas técnicas pedagógicas para lograrlos. En este contexto surge en educación con una fuerza avasallante, Internet, que puede realizar un aporte enorme a la educación, pero su optima utilización requiere de un individuo que desarrolle una gran capacidad para elaborar información creativamente, para ello los tradicionales métodos pedagógicos no pueden dar una adecuada capacitación. Esta realidad nos desafía, sólo con "creatividad" y "coraje creativo" podremos modificar en los sistemas educativos lo que corresponda. Internet representa un entronque histórico en educa- ción, que dividirá lo que era la educación antes de lo que será después de la aparición de Internet.

\section{La educación memorística}

En muchas instituciones educativas prevalece la educación "memorística", en ellas los métodos pedagógicos que se utilizan apuntan a poner el mayor esfuerzo en exigir al alumno que priorice en sus estudios el tomar la información que obtienen del docente y de los libros que este indica y grabarla en su memoria con la mayor fidelidad de la que sea capaz, para que alli este disponible durante el mayor tiempo posible. Ello ocurre en instituciones pertenecientes a todos los niveles de la educación formal, el estudiante suele ver reforzado ese modo de "estudiar" desde los 5 años hasta que termina la Universidad.

Los más importantes pedagogos insisten en que el objetivo primordial de la educación no debería ser transferirles in- 
formación para que la memoricen (la mente es considerada como un balde al cual hay que llenarlo), sino capacitarlos para que puedan "elaborarla creativamente", ello aportaría a formar individuos mas aptos en todos los aspectos de la vida.

\section{El aspecto geopolítico}

El formar alumnos capacitados para pensar mejor y más creativamente debería tener una especial importancia geopolitica para los gobernantes, sobre todo para los de los paises del tercer mundo, ya que estos no pueden competir con los paises desarrollados en tecnología ni en recursos económicos, pero si pueden lograr producir profesionales, científicos, empresarios, y ciudadanos en general, más creativos. Este aspecto, el de la creatividad humana, sigue siendo él más importante para el desarrollo económico, cultural y social de un país.

Los recursos económicos que se destinan a la educación son una excelente inversión que hace una sociedad, por ello deben destinarse a ella la mayor cantidad de fondos posibles, pero es responsabilidad de los gobernantes el que cada centavo produzca el máximo beneficio posible, para ello deben tomar "la decisión política" de establecer como objetivo educativo central capacitar a los alumnos para que puedan pensar mejor y más creativamente, y no para memorizar mejor, coherente con esta dirección deben estimularse los métodos pedagógicos que son de utilidad para este objetivo y excluirse los que lo perjudican.

\section{Metodologías pedagógicas democráticas vs. autoritarias}

Los dos objetivos educativos mencionados, capacitar para pensar creativamente o para memorizar, visualizan a la mente de diferente manera: en un caso como un farol, una bombilla, que hay que ayudar a encender y alimentar para que se prenda y de una luz cada vez más brillante; en el otro caso, la mente sería como un balde que hay que llenar (los padres se llevarían más de un disgusto si reflexionarían con más frecuencia, lo cual deberian hacer, sobre la utilidad de muchas de las cosas que la escuela primaria y media pone en la mente de sus hijos), estas distintas percepciones sobre la mente como farol o como balde, se manifiestan en la practica diaria docente en el aula utilizando métodos pedagógicos que en muchos aspectos son antagónicos.

El primero exige la utilización de una metodología pedagógica democráti$\mathrm{Ca}$, que genere una dinámica de aprendizaje en el cual pueda aflorar y desarrollar el alumno en forma adecuada el pensamiento creativo y su inteligencia emocional. El otro requiere de una metodología pedagógica autoritaria, esta línea educativa predomina con más fuerza en los paises en los cuales su organización política tuvo el sello del autoritarismo, pero métodos de enseñanza - aprendizaje de la pedagogía autoritaria están presentes, en mayor o menor medida, en todos los sistemas educativos del mundo, porque en todas las sociedades el pensamiento autoritario tiene su manifestación en diferentes ámbitos y también en el educativo, aportando a formar en los alumnos estructuras de personalidad autoritarias, 
aunque se les aya enseñado "teóricamente" las bondades de la democracia, de la tolerancia, de tratar de comprender y respetar al otro, prevalecerá en ellos la educación autoritaria que reciban en la familia y en la institución educativa a través de metodológicas de una pedagogía autoritaria.

Es importante resaltar que las metodologias pedagógicas autoritarias no sólo forman ciudadanos más autoritarios, también estructuran formas de pensar $e$ interactuar que disminuyen la capacidad de estudiar adecuadamente los conceptos científicos, los cuales por su naturaleza requieren para su mejor elaboración de mentes capacitadas en "pensar creativamente" y con "coraje creativo", esta capacitación también es indispensable actualmente para desempeñarse con éxito en el mercado laboral, los métodos de la pedagogía democrática son los que mejor pueden lograr este objetivo.

Con frecuencia se encuentra en una misma institución educativa la practica de métodos pedagógicos democráticos y autoritarios (suelen ir acompañados de un discurso democrático). Por lo general docentes bien intencionados aplican métodos que les enseñaron sin saber que son del tipo autoritario, y no conocen sus consecuencias negativas en la formación humana y académica del alumno. En cada institución educativa, los directivos, docentes, alumnos y padres, deben estar atentos para fortalecer los métodos pedagógicos democráticos y neutralizar los autoritarios (para que fácilmente puedan reconocer unos de otros el autor publico una guía con las características que tienen).

\section{Impacto de Internet en la educación}

La aparición de Internet impacta en esta situación, ocasionara profundos cambios en los métodos de enseñanza-aprendizaje y en los objetivos educativos. Le produce un gran golpe a la educación memorística, después de Internet a este tipo de educación no le queda argumento valido para justificar su existencia, ya no le es útil a la sociedad ni al alumno en su vida personal ni laboral, porque en la era de Internet "todos" con sólo apretar unas teclas tendrán acceso a "toda" la información que necesiten, y !actualizada al día!.

El principal valor agregado, la principal diferencia, entre unos alumnos $y$ otros, entre unos profesionales $y$ otros, entre unos empresarios y otros, ya no estará dada por quien tiene más información sino por quienes tendrán la capacidad de interpretar mejor la información y elaborarla más creativamente, produciendo un razonamiento de mejor calidad.

Internet posibilita, por primera vez en la historia de la educación, que la mente quede liberada de tener que retener una cantidad enorme de información, sólo es necesario comprender los conceptos sobre la dinámica de los procesos en los cuales una información esta encuadrada, ello permite utilizar métodos pedagógicos con los cuales el alumno puede aprender más y mejor en un año lo que le requería tres.

Ahora los docentes pueden destinar su esfuerzo y el de los alumnos en desarrollar más las capacidades mentales que les posibiliten a los estudiantes poder 
"comprender adecuadamente" la información y "elaborarla creativamente", pudiendo así producir una calidad superior de razonamiento.

Evaluaciones sobre la calidad educativa de los alumnos que egresan de la escuela media han demostrado que la mayoría no comprenden bien lo que leen y tienen serias deficiencias en poder razonar eficientemente.

Es importante resaltar que si a los alumnos que terminan la escuela media, en instituciones educativas en las cuales predomina la educación memorística, se les interroga sobre la información que con tanto esfuerzo memorizaron en los anteriores 12 años de "estudio", se comprobara que en la mayoría de los casos se les olvido en un porcentaje superior al $90 \%$, esto permite afirmar que la educación memorística también fracasa en lograr su objetivo, además de perjudicar la formación de un alumno con pensamiento creativo.

Las personas que no estén capacitadas para elaborar con eficiencia, creativamente, la cuantiosa y variada información que pueden obtener en Internet, no podrán utilizar en forma optima este extraordinario instrumento, verán empobrecido el proceso de convertir la información en conocimiento, en su desempeño laboral el nivel de ignorancia que ello produce permite hablar de un tipo de analfabeto (el del tipo cuatro) que será cada vez más rechazado en las empresas.

\section{Los 4 tipos de analfabetos}

Hay 4 tipos de analfabetos: un primer tipo es el que no sabe leer. Un se- gundo tipo es el que sabe leer pero no comprende bien lo que lee (ya señale que la mayoría de los alumnos presentan esta deficiencia). El analfabeto del tercer tipo es el que comprende bien lo que lee, pero no tiene la "motivación" suficiente para leer aquello que pueda aportar a su desarrollo, por lo tanto se queda en un nivel importante de ignorancia (es conveniente tener presente que comprender bien lo que se lee da "información" pero no "conocimiento"). El cuarto tipo de analfabeto es el que puede comprender eficientemente lo que lee, pero no puede elaborar la información creativamente, sólo de esta forma se puede con la información obtener conocimiento (si bien la referencia es al leer, es únicamente por ser ese medio el que suele ser él más importante para profundizar un tema, pero los mismos problemas se presentan en poder comprender adecuadamente y elaborar eficientemente la información que proviene de fuentes audiovisuales).

Un pais tiene mayor riqueza en $\mathrm{Ca}$ pital Humano en la medida en que menos analfabetos tenga en cada una de estas categorias.

\section{La conveniencia de capacitar a los docentes en métodos para el desarrollo de la creatividad}

Internet producirá profundos cambios en diferentes ámbitos, de la magnitud como los que ocasiono la invención de la imprenta, la electricidad, el automóvil, el avión, el teléfono, la televisión, y muchas otras creaciones del hombre que produjeron revoluciones tecnológicas. En educación, la pedagogía que utiliza méto- 
dos de enseñanza-aprendizaje para transferir información para que sea memorizada obstaculiza la optima utilización de los alumnos de las posibilidades de Internet, ello perjudica los esfuerzos en mejorar la calidad educativa.

Se debe poner más énfasis en capacitar a los alumnos para que puedan de una forma más eficiente elaborar creativamente la información, para ello los organismos y las instituciones educativas deberian constituir equipos con expertos en desarrollo del pensamiento creativo para que capaciten a los docentes en los métodos pedagógicos que deben emplear para lograr el objetivo mencionado. 